\title{
Symptomatic form of hemochromatosis type 1
}

INSERM

\section{Source}

INSERM. (1999). Orphanet: an online rare disease and orphan drug data base.

Symptomatic form of hemochromatosis type 1. ORPHA:465508

Symptomatic form of hemochromatosis type 1 is a rare, hereditary hemochromatosis characterized by inappropriately regulated intestinal iron absorption which leads to excessive iron storage in various organs and manifests with a wide range of signs and symptoms, including abdominal pain, weakness, lethargy, weight loss, elevated serum aminotransferase levels, increase in skin pigmentation, and/or arthropathy in the metacarpophalangeal joints. Other commonly associated manifestations include hepatomegaly, cirrhosis, liver fibrosis, hepatocellular carcinoma, restrictive cardiomyopathy and/or diabetes mellitus. 